\title{
From milk to rifampicin and back again: history of failures and successes in the treatment for tuberculosis
}

\author{
Michele A Riva
}

The millennial flight against tuberculosis has been characterized by several defeats. Roman physicians suggested to consumptives better nutrition, sea voyages and change of air, while, during the Middle Ages, 'royal touch' were considered as an effective remedy for scrofula. In the following centuries, phthisis was cured using old herbal preparations and new chemical compounds, mainly aimed at soothing symptoms; in addition, harmful approaches (for example, bleeding and purging) were commonly accepted, according to medical theories of that time. In the second part of the nineteenth century, the discovery of the contagious nature of consumption (Villemin, Koch) addressed physicians and scientists toward often-unsuccessful remedies, such as antiparasitic treatment, immunomodulants, vaccination and serum therapy. In that period only sanatorium regimenbased on aerotherapy, bed rest, better nutrition, sunbathing and moderate physical exercise-appeared to provide first partial successes. In these structures, more invasive approaches were also employed, such as lung collapse surgical interventions (for example, phrenicotomy, thoracoplasty) and artificial pneumothorax. Since the second part of the twentieth century, the industrialization of pharmacotherapy, the development of antimicrobial chemotherapy and the introduction of new antibiotics (streptomycin, isoniazid, para-aminosalicylic acid, ethambutol and pyrazinamide) deeply revolutionized treatment for tuberculosis, allowing to achieve important successes. In this same period, the figure of Piero Sensi (1920-2013) deserves to be recalled for his contribution in the development of rifampicin that played a decisive role in the chemical fight against the white plague. Nowadays, antibiotic resistance is an emerging problem, representing a new challenge for physicians and scientists who sometimes re-proposed old 'historical' approaches.

The Journal of Antibiotics (2014) 67, 661-665; doi:10.1038/ja.2014.108; published online 6 August 2014

Efforts to treat tuberculosis over the centuries have been largely tales of frustration. ${ }^{1}$ Prior to the introduction of the first antimicrobial agents, tuberculosis management only relied upon herbal poultices and chemical preparations, dietary intervention and climatic prescription (aerotherapy and heliotherapy), sometimes also using more harmful than beneficial treatments (that is, bleeding and purging). ${ }^{2}$ Since the 1940 s, chemotherapy has played a decisive role in controlling endemic tuberculosis, contributing to reduce its mortality and morbidity, especially in the Western countries. In the history of the millennial fight against the 'white plague', the often-forgotten figure of Piero Sensi (1920-2013) deserves to be remembered due to his fundamental contribution in the development of one of the most effective antimycobacterium agents, rifampicin, that dramatically changed the natural history of tuberculosis. The first anniversary of Sensi's death provides us with a timely opportunity to commemorate this Italian scientist and his work, by an historical analysis of the failures and the successes of the treatment for tuberculosis over the centuries.
FIRST APPROACHES: MILK, VOYAGES AND ROYAL TOUCH

Tuberculosis is a very ancient scourge, well known in the GrecoRoman world, where it was called as 'phthisis' ('tabes' in Rome) or 'consumption.' At that time, this condition was looked upon as incurable and hopeless, especially if the illness was contracted at a young age, as well testified by a Hippocratic aphorism on tuberculous spondylitis: 'such persons as become hump-backed from asthma or cough before puberty die' (Aphorisms, VI, 46). ${ }^{4}$ For tuberculosis treatment, Roman physicians generally suggested a dietetic regimen based on milk, better nutrition and a change of air, favoring NorthAfrican climate in particular. For instance, the Roman encyclopedist Aulus Cornelius Celsus (ca 25 BC-ca 50) stated that 'opus est, si vires patiuntur, longa navigatione, caeli mutatione, sic ut densius quam id est, ex quo discedit aeger, petatur: ideoque aptissime Alexandriam ex Italia itur' ('If the strength allows of it, a long sea voyage is necessary with a change of air, of such a kind that a denser climate should be sought than that which the patient quits; hence the most suitable is the voyage to Alexandria from Italy', 'De Re Medica', III, 22.8). ${ }^{4}$ In his book 'De curatione diuturnorum morborum', Aretaeus of 
Cappadocia, a Greek physician who worked in Rome during the first century, recommended to phthisical patients to 'travel to high altitudes, travel by sea, eat a good diet and drink plenty of milk'. These theories also influenced the most eminent physician in the Roman Empire, Galen (ca 129-200), who also suggested fresh air, milk and sea voyages for the treatment of this condition. ${ }^{4}$

During the Middle Ages and the Renaissance, the high prevalence of other infectious diseases (for example, leprosy, bubonic plague and syphilis) reduced the interest of physicians toward tuberculosis that curiously seemed to disappear from the European continent. ${ }^{5}$ Actually, this disease and some of its clinical manifestations-such as scrofula, that is, cervical lymphadenitis associated with mycobacterial infection-continued to be widespread in the population, especially in the poorest classes. Until the beginning of the nineteenth century, scrofula was generally treated with the legendary 'royal touch. ${ }^{6}$ French and English monarchs were indeed credited to heal scrofulous individuals, touching them in a well-codified ritual, where the sentence 'the King touches you, God cures you' ('Le Roy te touche et Dieu te guérit' in French) also wanted to confirm the legitimacy of the sovereigns and the divine origin of their powers. ${ }^{4}$ Royal touch was not the only method used to treat scrofula. In that period, barbers and surgeons suggested to remove the suppurated glands, while physicians trained at the 'Schola Medica Salernitana' recommended the local application of poultices of porcine bile or figs. However, during the Middle Ages, the remedies against pulmonary tuberculosis continued to be mainly those suggested by the Roman physicians (travel, change of air and better nutrition). ${ }^{4}$

\section{EARLY 'SCIENTIFIC' FAILURES: FROM BLOODLETTING TO THE FIRST CHEMICAL COMPOUNDS}

During the Modern Age and in the first part of the nineteenth century, the approach to the care of tuberculosis was constantly changing, according to the different position of each doctor and his adhesion to different medical doctrines. Therefore, it comes as no surprise that, between the eighteenth and nineteenth centuries, consumption was also cured using harmful approaches, such as bleeding and purging. ${ }^{1}$ Bloodletting, leeches and counter irritants like cupping and blistering were commonly employed in the treatment of these patients, according to 'stimulus and contra-stimulus theory', developed in those years by John Brown (1735-1788) and Giovanni Rasori (1766-1837). ${ }^{7}$

Between 1820 and 1830s, the dramatic rise of tuberculosis in the Western countries led European physicians and scientists to seek new remedies to fight this infectious disease. New chemical compounds and old herbal preparations were often used simultaneously in the nineteenth-century pharmacopoeia. Cod liver oil, chest massages with acetic acid and cantharidin tincture, pills of copper sulfate, morphine and creosote were generally prescribed in the United Kingdom and in the Northern part of continental Europe. ${ }^{8}$ In the same countries, physicians also recommended the inhalation of vapors of tar, iodine, chlorine, hemlock, turpentine, prussic acid and hydroiodate of potassium and other stimulant or sedative substances. ${ }^{8}$ In Italy and in Southern Europe, consumptives were ordered to swallow decoctions of Iceland and Irish moss, extract of aconite, seeds of water dropwort, sulfur and calcium hydroxide and tar water, and to cover their bodies with myrrh tincture, ointment of emetic tartar (Autenrieth's ointment) and leaves of belladonna in opioid infusion. ${ }^{8}$ All these remedies were mainly aimed at treating respiratory symptoms of phthisis, being able to soothe albeit only partially patients' sufferings. Better nutrition and change of air still appeared to be the only effective means to prolong the duration of life of individuals affected with tuberculosis, although generally only rich people and upper class members could follow these prescriptions.

The failure of the mid-1800 medical science in tuberculosis treatment may be well summarized by the words of the renowned British doctor, James Clark (1788-1870): 'Respecting the treatment of consumption, we must admit the humiliating truth, that there is no reason to believe the physicians of the present day more successful than their predecessors were ten, nay twenty centuries ago.9

\section{ANTIMICROBIAL TREATMENT BETWEEN HOPES AND DISILLUSIONS}

Until the mid-1800s the limitations in remedies against tuberculosis may be partly justified by lack of knowledge on the etiology and the pathogenetic mechanisms of this condition. Indeed, in Northern Europe tuberculosis was still considered a heritable and noncommunicable disease, where as in Southern Europe it was felt to be infectious in nature. ${ }^{10}$ In the second part of the nineteenth century, the parallel development of clinical practice, preventive medicine and laboratory research supported medical practitioners and scientists to understand and better fight phthisis. The introduction of the term 'tuberculosis' by Johann L Schönlein (1793-1864) to collect all the multiple localization of this disease (1839), the diffusion of Laennec's stethoscope in clinical practice, and the institution of the first hospitals entirely devoted to consumptives - for example, 'San Luigi Gonzaga' in Turin (1818) and 'Brompton Hospital for Consumptives' in London (1841) - contributed to better clarify the pathogenesis of this condition and to cure patients affected with this disease. ${ }^{11}$ In 1865, a French military surgeon, Jean-Antoine Villemin (1827-1892), convincingly proved that tuberculosis was an infectious disease, by inoculating a rabbit with purulent material from an infected individual. ${ }^{12}$ His findings were initially ignored by the scientific community, even if microbiological etiology of tuberculosis was also postulated by other scientists, such as the English epidemiologist William Budd (1811-1880). In 1882, the identification of Mycobacterium tuberculosis by Robert Koch (1843-1910) definitively demonstrated the infectious origin of this condition, dramatically changing the history of tuberculosis and its treatment. ${ }^{12}$ Finally, at the turn of the twentieth century, the diffusion of chest radiograph, thanks to the studies of Wilhelm C Röntgen (1845-1923), allowed a more accurate and rapid diagnosis of this disease.

After the recognition of microbial etiology, the illusion that an effective cure was within reach collided with reality, which was somewhat different. Antiparasitic treatment, based on inhalation of classic antiseptics, immediately appeared as ineffective, as the alveolar penetration of these substances was low and Koch's bacillus was very resistant to them. In 1899 the Italian pharmacologist Vincenzo Cervello (1854-1918) introduced 'igazol', a compound of formaldehyde with trioxymethylene and some iodine derivatives, that could be administered through a vaporizer. ${ }^{8}$ According to Cervello's theories, the effectiveness of igazol would be related to the antioxidant action of formaldehyde on tubercle bacilli; actually the results in clinical practice were less than modest, leading igazol to be soon abandoned. ${ }^{8}$

In the last decade of the nineteenth century and at the beginning of the last century, the development of immunology led scientists and physicians to conduct researches in the field of vaccination and serum therapy, which, however, proved fruitless. In 1890, during the Tenth International Medical Congress in Berlin, Koch announced that he had found a substance that could inhibit the growth of the tubercle bacillus in laboratory cultures and in guinea-pigs. This mysterious preparation was a glycerin concentrate extract of tubercle bacilli, called by the German bacteriologist 'tuberculin' and renamed by 
contemporary mass media as 'Koch's lymph. ${ }^{13}$ After first apparently positive results published by Koch himself, injections of this substance rapidly came into vogue as a treatment for tuberculosis; almost as rapidly shown to be ineffective. ${ }^{14}$ As well known, tuberculin was later successfully utilized as a screening test for the presence of presymptomatic tuberculosis, thanks to the contributions of Clemens von Pirquet (1874-1929) and Charles Mantoux (1877-1947). ${ }^{15}$

After 'tuberculin fiasco', another line of research deceived tuberculosis patients. In $1890 \mathrm{~s}$, several studies reported positive results achieved with immune sera, generated by immunizing or infecting animals with mycobacteria. At that time, indeed, serum therapy started to show the first successes in the fight against infectious diseases, leading Emil A von Behring (1854-1917) to win the first Nobel Prize in Physiology or Medicine in 1901 for the development of serum therapies against diphtheria and tetanus. In 1895, Edoardo Maragliano (1849-1940) from Genoa (Italy) first reported the use of horse tuberculosis antiserum, prepared by immunizing various animals with a mixture of two preparations of mycobacterial substances. ${ }^{16}$ The Genoese physician proved that the serum had a prophylactic and protective effect in guinea-pigs, due to its antitoxic and bactericidal properties. The effectiveness of Maragliano's serum, however, was not confirmed in humans and, similarly, no consistently successful serum formulation against tuberculosis was ever developed by other scientists. ${ }^{16}$

\section{WOOL, BED, MILK: EARLY SUCCESSES IN SANATORIUM ASSISTANCE}

Owing to the failures of science and clinical practices, only the suggestions of the Roman physicians appeared still effective. Individuals with tuberculosis needed high-quality assistance, bed rest and better nutrition, as well summarized by the Italian aphorism 'Lana, letto, latte' (wool, bed, milk). ${ }^{17}$ So, at the turn of the last century, in all of Europe the development of new institutions, the sanatoria, contributed to control the rise of this infectious disease. The establishment of these structures was mainly linked to new theories on climatic benefits to tuberculosis, developed during the second part of nineteenth century. According to these ideas, fresh air and mountain climate had to be preferred to warmer and maritime climate. $^{11}$ In 1856, the Swiss physician Henri-Clermond Lombard (1803-1895), one of the founders of 'Medical Geography' as a discipline, published the first study to support the benefits of mountain climate. Lombard claimed that the reduction of the blood oxygen tension, due to the rarefaction of air at higher altitude, would have been able to induce a 'respiratory diet' in patients affected with tuberculosis, preventing the evolution of the disease. ${ }^{11}$ These theories, also supported by the low prevalence of tuberculosis in people living in the mountains, led to establish the first high-altitude sanatoria, such as the 'Brehmersche Heilanstalt für Lungenkranke' in Görbersdorf (Silesia), founded by Hermann Brehmer (1826-1889). The life of patients and the treatment offered in Schatzalp sanatorium, built by Alexander Spengler (1827-1901) in Davos (Switzerland), were well described in Thomas Mann's novel 'The Magic Mountain' ('Der Zauberberg') in 1924. ${ }^{11}$ Owing to these apparent therapeutic successes in sanatoria located in mountain resorts, 'aerotherapy' became a cornerstone for the treatment of tuberculosis, spreading the model of sanatorium care throughout the world. In these hospitals, the most common treatments were better nutrition and sunbathing (heliotherapy) that probably contributed to restore vitamin D deficiency, essential for macrophage function. Moreover, bed rest and moderate physical exercise would improve perfusion to areas of the lung most affected by cavitary tuberculosis. ${ }^{2}$ More invasive approaches were also used in sanatorium: surgeons continued to hold to the traditional philosophy that only a resting lung could heal itself, so they performed several different surgical procedures to collapse the diseased lung. Surgical 'compression therapies' (or 'lung collapse therapies') included phrenicotomy, thoracoplasty and removal of part of the organ, such as lobectomy and pneumoectomy. ${ }^{11}$ Another way to collapse or deflate the lung was by a less-invasive technique, called 'artificial pneumothorax'. In 1882, annus mirabilis in the history of tuberculosis (the same year of the discovery of tubercle bacillus), the Italian physician Carlo Forlanini (1847-1918) proposed the intra-pleural introduction of gases (nitrogen) to collapse the diseases lung. ${ }^{18}$ Lying quietly in the chest like a deflated balloon, the lung had a chance to heal; later, it could be allowed to inflate again and breathe as before. The first artificial pneumothorax was successfully induced in 1888, but only after 1912 this treatment came to be widely adopted in Europe and in the United States. ${ }^{18}$ Forlanini's pneumothorax may be looked upon as a 'iatro-mechanic' response to the dramatic failures of the nineteenth-century pharmacology in the treatment for phthisis.

\section{FROM THE ‘GOLDEN FIASCO’ TO THE GOLDEN ERA OF ANTIBIOTICS}

Despite the modest successes of the sanatorium approach, in the mid1900s tuberculosis continued to be a plague for human society, powered by deprivation and poor hygienic conditions due to the two global conflicts. In particular, during the First World War pulmonary tuberculosis decimated European soldiers in trenches, so that a large number of veterans were admitted to the sanatoria in the post-war period. ${ }^{19}$ As well known, in the first part of the twentieth century, first achievements were obtained in the field of antimicrobial chemotherapy. In 1905 Paul Erlich (1854-1915) developed arsphenamine against syphilis, while 30 years later Gerhard Domagk (1895-1964) and its Prontosil marked the beginnings of the sulfonamides era. Although some sulfonamides and their derivatives (for example, promizole) were shown to inhibit mycobacteria both in vitro and in vivo, ${ }^{2}$ an effective antimicrobial treatment for tuberculosis still seemed to be utopic. Most physicians still considered tuberculosis 'a disease best approached by modifying the host's immune response with agents such as tuberculin.' ${ }^{2}$ For this reason, according to these theories, alternative immune-therapies and new preventive measures were tried between 1920 and 1940. In 1921, the 'Vaccin Bilié de Calmette et Guérin' (now BCG vaccine) was first used in humans, being developed by the French bacteriologist Albert Calmette (1863-1933) and his veterinarian colleague Camille Guérin (1872-1961), by sub-culturing virulent strains of mycobacterium for more than 10 years and producing a form attenuated enough to be considered safe for use as a vaccine. ${ }^{20}$ Mass vaccination with BCG did not start until after World War II. However, the efficacy of vaccination against pulmonary tuberculosis appeared to be variable, so demonstrating its limited utility as a preventive measure. In 1925, Holger Mollgaard (1885-1973) from Copenhagen introduced a gold treatment for tuberculosis, based on sanocrysin, a double thiosulfate of gold and sodium. Treatment of pulmonary tuberculosis with this compound became soon very popular, despite consistently negative experimental results. ${ }^{21}$ In 1934, a controlled trial, completed in the United States, proved the toxic effects of this compound, representing yet another failure of antituberculosis chemotherapy. ${ }^{21}$

However, with the rise of industrialization of pharmacotherapy things began to change. Initially, physicians produced and prescribed their own drugs, but they were limited when the extraction of alkaloids became more complex, requiring solvents, distillation and 
crystallization. Pharmaceutical companies could purchase new machineries and hire laboratory researchers, so producing new synthetic and standardized drugs, protected by patents and trade names. These new substances had to be tested by pharmacologists and their mechanism of action had to be well understood, so encouraging the scientific research. So, in this new phase of history of tuberculosis treatment, pharmaceutical industries played a decisive role in the discovery of new drugs, as demonstrated by the fact that most of the new antituberculosis antibiotics-including rifampicin-were developed by teams of pharmacologists in the research unit of pharmaceutical firms. Indeed, the industrialization of pharmacotherapy allowed researchers to more easily collaborate; furthermore, with the support of large-scale industrial technologies of the time, new medicines could be distributed in each country without problems, while they would have been only available to the local population and local physicians previously. It is not a coincidence that one of the first most effective antibiotic, penicillin, was industrialized for mass treatment in this period.

So in this context, only 10 years after the 'golden fiasco', in 1944 the first two drugs with clear effects Mycobacterium tuberculosis, streptomycin and para-aminosalicylic acid (PAS), were simultaneously discovered. In that year, Jörgen E Lehmann (1898-1989), a Danishborn Swedish physician and chemist, synthesized the para-amino salt of salicylic acid with the help of the Swedish pharmaceutical company Ferosan. $^{22}$ A few months before, in the United States Selman A Waksman (1888-1973) and Albert I Schatz (1920-2005) had isolated streptomycin from Streptomyces griseus and proved its activity against human mycobacterium. ${ }^{23,24}$ At the end of World War II, the United States Army experimented with streptomycin to treat life-threatening infections at a military hospital in Michigan, showing the first unexpected results, and then confirming the advantage of associating this drug with PAS. Indeed, a famous clinical trial conducted in 1948 demonstrated a lower rate of streptomycin resistance in the streptomycin-PAS treated patients. ${ }^{25,26}$ These results provided the first evidence of the importance of combination therapies to prevent drug resistance.

The next important step forward was the discovery of the antituberculosis activity of isoniazid. In 1951 it was demonstrated simultaneously and independently in three different laboratories (Squibb, Hoffmann La Roche and Bayer) that this remarkably simple chemical compound, isonicotinyl hydrazine, first synthesized by two Prague chemist Hans Meyer and Josef Mally in 1912, had a high degree of anti-tuberculosis activity in laboratory animals. After initial skepticism, isoniazid proved to be the most efficacious drug yet discovered, as confirmed in various clinical trials. ${ }^{27}$ The addiction of isoniazid to PAS and streptomycin ('triple therapy) further reduced the rates of drug resistance and increased the effectiveness of the treatment, even if a 24-month period of continuous therapy was still requested. ${ }^{28}$ At the end of 1950s, a study conducted in Madras (South India) deeply revolutionized tuberculosis treatment, demonstrating that the results of domiciliary chemotherapy were comparable to those of sanatorium treatment and that it would be appropriate to treat tuberculosis patients at home. ${ }^{29}$

In 1960s the reduction in the duration of treatment to 18 months was allowed by the replacement of PAS by a much better tolerated drug, ethambutol, discovered by Lederle laboratories in the United States in $1961 .^{30}$ In this decade research into antituberculosis agents continued, resulting in the identification of a large number of compounds, now generally used as second-line drugs in tuberculosis treatment: viomycin, cycloserine and terizidone, kanamycin and amikacin, capreomycin and the thioamides ethionamide and prothionamide. ${ }^{2}$ In that same period, the main advance in therapy was the introduction of rifampicin. In 1957 a new Streptomyces species, S. mediterranei (now renamed Amycolatopsis mediterranei), was isolated by the research group of the Italian Lepetit Laboratories (Milan), headed by Piero Sensi and Maria Teresa Timbal (1925-1969), from a soil sample from a pine forest near St Raphaël (France). ${ }^{31}$ This microorganism produced a large family of structurally related compounds with various degree of antimicrobical activity on several pathogens. They were called, collectively, 'rifamycin', after the title of the then very popular noir film 'Rififi' directed by the American filmmaker Jules Dassin in 1965. ${ }^{32}$ Although fairly active in vitro, the compounds showed modest or no activity in vivo. Sensi's group realized that chemical modifications in certain parts of the original molecule let to compounds with increased in vivo activity. In 1960s, a research agreement between Lepetit and Ciba was established to produce a large number of semisynthetic derivatives of the natural rifamycin with the aim of generating a compound with the following characteristics: oral absorption, more prolonged therapeutic blood levels and higher activity in the treatment of mycobacterial and Gram-negative bacterial infection. ${ }^{33}$ Among several hundred semisynthetic rifamycin derivatives, preliminary studies indicated that rifampicin (rifampin USAN), synthesized in 1965 in Milan, possessed most of the abovementioned properties. ${ }^{33}$ In 1970s the introduction of rifampicin in tuberculosis therapy allowed to half the duration of treatment from 18 to 9 months. Finally, among antituberculosis antibiotics pyrazinamide should be mentioned. This drug, first synthetized by Dalmer and Walter in 1936 and rediscovered in 1972, was found to reduce the duration of treatment to 6 months, if associated with isoniazid and rifampicin (short-course chemotherapy). ${ }^{34}$

\section{OLD PROBLEMS AND OLD SOLUTIONS: MODERN CHALLENGES IN TUBERCULOSIS TREATMENT}

After the introduction of rifampicin and pyrazinamide, the success of chemotherapy and of short-course regimen led to a gradual lack of interest in tuberculosis drug research. Scientific attention toward this disease was resuscitated only in 1990s under the devastating impact of AIDS epidemics and the dramatic interaction between HIV and M. tuberculosis. ${ }^{1}$ Drug resistance, an old problem in the treatment for tuberculosis, apparently solved by drug combination in 1950-1960s, became an emergency not only in poor and endemic countries. In particular, cases of multidrug-resistant tuberculosis, defined as tuberculosis that is resistant to at least isoniazid and rifampicin, are dramatically increasing in several countries. 'Directly Observed Therapy' (DOT) and 'Directly Observed Treatment, Short-course' (DOTS) strategies, originally developed by Karel Styblo (1921-1998) in developing countries in 1970-1980s, appeared to be a solution to reduce noncompliance and abandonment of treatment. ${ }^{35}$

Curiously, in recent years some 'old solutions' were also proposed to contrast drug-resistant strains, such as the establishment of sanatorium-like structures for admission of incurable cases, ${ }^{36}$ the research of new immunomodulating agents (interleukins, interferon, etc.) and vaccines, ${ }^{1}$ new experiments on serum therapy ${ }^{16}$ and on artificial pneumothorax. ${ }^{37}$ Similarly, the recent demonstration that IgA purified from human colostrum protects against M. tuberculosis infection in an experimental mouse model could make us smile thinking that Roman physicians might have been right in prescribing milk (even if non-pasteurized cattle milk continued to be considered as an important source of tuberculosis infection in developing countries). ${ }^{38}$ These 'historical' proposals often generated a 
heated debate on scientific journals and during international conferences, ${ }^{39}$ suggesting that the knowledge of the history of treatment for tuberculosis, its successes and its failures should be well recalled, specially to new generations of scientists and physicians. Finally, in this long history, extraordinary figures such as Piero Sensi may testify to the younger researchers that only determination and dedication lead to achieve considerable successes in laboratory and clinical medicine. As aforementioned, the amazing successes of the golden era of antibiotics were the results of collaboration between pharmaceutical industries and academic research institutes. As in other fields of biomedical and laboratory research, ${ }^{40}$ the discovery of new antituberculosis drugs were not related to a single investigator, but to a team of scientist who worked in the same laboratory. The studies and works of the twentieth-century scientists (Sensi, Timbal, Lehmann, Waksman, Schatz, etc.) and their collaboration with private research centers (Lepetit, Ciba, Lederle, Squibb, Bayer, Hoffman-La Roche, etc.) ought to make modern scientific world reflect on how the discovery of new antimicrobial agents can be nowadays threatened by the lack of research in the pharmaceutical industries.

1 Iseman, M. D. Tuberculosis therapy: past, present and future. Eur. Respir. J. Suppl. 36, 87s-94s (2002)

2 Diacon, A. H., von Groote-Bidlingmaier, F. \& Donald., P. R. From magic mountain to table mountain. Swiss Med. Wkly. 142, w13665 (2012).

3 Grmek, M. D. Les maladies à l'aube de la civilisation occidentale (Payot, Paris, 1983).

4 Bernardi, A., Barbuti, N. \& Montagna, M. T. II morbo oscuro. Storia scientificoletteraria della tubercolosi dall'antichità ai giorni nostri 23-31 (Mario Adda Editore, Bari, 2012).

5 Daniel, T. M. The history of tuberculosis. Respir. Med. 100, 1862-1870 (2006).

6 Dossey, L. The royal touch: a look at healing in times past. Explore (NY) 9, 121-127 (2013).

7 Cosmacini, G. L'arte lunga. Storia della medicina dall'antichità ad oggi 326-327 (Laterza, Roma-Bari, 2008)

8 Tognotti, E. II morbo lento. La tisi nell'Italia dell'Ottocento (Franco Angeli, Milan, 2012).

9 Clark, J. The influence of climate in the prevention and cure of chronic disease, more particularly of the chest and digestive organs (Thomas and George Underwood, London, 1829).

10 Riva, M. A., Ploia, P. R., Rocca, S. \& Cesana, G. 'Phthisiophobia': the difficult recognition of transmission of tuberculosis to health care workers. Med. Lav. 104, 359-367 (2013).

11 Riva, M. A. In Dal Mal sottile alla tubercolosi resistente. Un secolo di sanatori in Valtellina (ed. Del Curto, D.) 45-49 (Grafiche Rusconi, Bellano, 2012).

12 Cambau, E. \& Drancourt, M. Steps towards the discovery of Mycobacterium tuberculosis by Robert Koch, 1882. Clin. Microbiol. Infect. 20, 196-201 (2014).

13 Friedman, M. \& Friedland, G. W. Medicine 10's Greatest Discoveries (Yale University Press, New Haven (CT), 1998).

14 Sbarbaro, J. A. \& Iseman, M. D. 'Koch's lymph' 107 years later-an oldie but not a goldie. Clin. Infect. Dis. 25, 664-665 (1997).
15 Yang, H., Kruh-Garcia, N. A. \& Dobos, K. M. Purified protein derivatives of tuberculin-past, present, and future. FEMS Immunol. Med. Microbiol. 66, 273-280 (2012).

16 Glatman-Freedman, A. \& Casadevall, A. Serum therapy for tuberculosis revisited: reappraisal of the role of antibody-mediated immunity against Mycobacterium tuberculosis. Clin. Microbiol. Rev. 11, 514-532 (1998).

17 Manzini, E. \& Di Mauro, S. In Dal Mal sottile alla tubercolosi resistente. Un secolo di sanatori in Valtellina (ed. Del Curto, D.) 39-43 (Grafiche Rusconi, Bellano, 2012).

18 Sakula, A. Carlo Forlanini, inventor of artificial pneumothorax for treatment of pulmonary tuberculosis. Thorax 38, 326-332 (1983).

19 Cosmacini, G., De Filippis, M. \& Sanseverino, P. La peste bianca. Milano e la lotta antitubercolare (1882-1945) (Franco Angeli, Milan, 2004).

20 Hawgood, B. J. Albert Calmette (1863-1933) and Camille Guérin (1872-1961): the C and G of BCG vaccine. J. Med. Biogr. 15, 139-146 (2007).

21 Benedek, T. G. The history of gold therapy for tuberculosis. J. Hist. Med. Allied Sci. 59, 50-89 (2004).

22 Lehmann, J. Twenty years afterward: historical notes on the discovery of the antituberculosis effect of paraaminosalicylic acid (PAS) and the first clinical trials. Am. Rev. Respir. Dis. 90, 953-956 (1994).

23 Schatz, A., Bugie, E. \& Waksman, S. A. Streptomycin, a substance exhibiting antibiotic activity against Gram-positive and Gram-negative bacteria. Proc. Soc. Exp. Biol. Med. 55, 66-69 (1944)

24 Daniel, T. M. Selman Abraham Waksman and the discovery of streptomycin. Int. J. Tuberc. Lung Dis. 9, 120-122 (2005).

25 Medical Research Council. Streptomycin treatment of pulmonary tuberculosis. Br. Med. J. 2, 769-782 (1948)

26 Fox, W. \& Sutherland, I. A five-year assessment of patients in a controlled trial of streptomycin, para-aminosalicylic acid, and streptomycin plus para-aminosalicylic acid, in pulmonary tuberculosis. Q. J. Med. 25, 221-243 (1956).

27 McDermott, W. The story of INH. J. Infect. Dis. 119, 678-683 (1969).

28 Medical Research Council. Various combinations of isoniazid with streptomycin or with P.A.S. in the treatment of pulmonary tuberculosis. Br. Med. J. 1, 435-445 (1955).

29 Tuberculosis Chemotherapy Centre. A concurrent comparison of home and sanatorium treatment of pulmonary tuberculosis in South India. Bull. World Health Organ. 21, 51-144 (1959).

30 Doster, B., Murray, F. J., Newman, R. \& Woolpert, S. F. Ethambutol in the initial treatment of pulmonary tuberculosis. U.S. Public Health Service tuberculosis therapy trials. Am. Rev. Respir. Dis. 107, 117-190 (1973).

31 Sensi, P. History of the development of rifampin. Rev. Infect. Dis. 5 (Suppl 3), S402-S406 (1983).

32 Aronson, J. That's show business. Br. Med. J. 319, 972 (1999).

33 Sensi, P. In Chronicles of Drug Discovery (eds Bindra, J, S. \& Lednicer, D.) 201-221 (Wiley, New York, 1982).

34 Hong Kong Chest Service, BMR Council. Controlled trial of 6-month and 8-month regimens in the treatment of pulmonary tuberculosis: the results up to 24 months. Tubercle 60, 201-2010 (1979).

35 Bayer, R. \& Wilkinson, D. Directly observed therapy for tuberculosis: history of an idea. Lancet 345, 1545-1548 (1995).

36 Dheda, K. \& Migliori, G. B. The global rise of extensively drug-resistant tuberculosis: is the time to bring back sanatoria now overdue? Lancet 379, 773-775 (2012).

37 Motus, I. Y. et al. Reviving an old idea: can artificial pneumothorax play a role in the modern management of tuberculosis? Int. J. Tuberc. Lung Dis. 10, 571-577 (2006).

38 Alvarez, N. et al. Passive administration of purified secretory IgA from humancolostrum induces protection against Mycobacterium tuberculosis in a murine model of progressive pulmonary infection. BMC Immunol. 14 (Suppl 1), S3 (2013).

39 Hughes, J., Cox, H. \& Ford, N. Sanatoria for drug-resistant tuberculosis: an outdated response. Lancet 379, 2148 (2012).

40 Riva, M. A. et al. Histochemistry: historical development and current use in pathology. Biotech. Histochem. 89, 81-90 (2014). 